\title{
Apoio social a gestantes adolescentes: desvelando percepções
}

\author{
Social support to pregnant adolescents: clarifying perceptions
}

Tatiane Schwartz ${ }^{1}$

Renata Vieira ${ }^{2}$

Lorena Teresinha Consalter Geib ${ }^{3}$

${ }^{1}$ Hospital São Vicente de Paulo. Rua Teixeira Soares 808, Centro. 99010-080

Passo Fundo RS.

tati_schwartz@hotmail.com ${ }^{2}$ Curso de Enfermagem,

Universidade de Passo

Fundo.

${ }^{3}$ Instituto de Ciências

Biológicas, Universidade de

Passo Fundo.
Abstract This descriptive-exploratory study using a qualitative approach was undertaken to describe the perceptions of pregnant adolescents in relation to social support provided during pregnancy. Twelve adolescents in their first pregnancy who frequented the outpatient health service in Passo Fundo in the state of Rio Grande do Sul (Brazil) participated in the study. The data was obtained by semi-structured interviews, genograms and ecomaps and was assessed by thematic analysis. It highlighted the need for support to overcome the fears and challenges of motherhood. The mothers and partners were perceived as the main sources of support in affective and material terms. Common sense knowledge prevailed in the information dimension and pregnancy as a mediator in the reconciliation with the father fulfilled the emotional dimension. The perception of the dimension of positive social interaction was blurred by self-imposed isolation. Thus the adolescent's perception of the social support received is clear in relation to the family nucleus and includes the people in the family circle. The network of care outside the family, including the healthcare services, is tenuous and generated the perception of psychosocial difficulties. This reveals the need for greater investment of primary healthcare professionals in the inclusion of first-time-pregnancy adolescents in social care groups, which ensure the healthy progress of the pregnancy.

Key words Adolescence, Gestation, Social support
Resumo Com o objetivo de descrever a percepção das gestantes adolescentes em relação ao apoio recebido durante a fase gestacional, realizou-se este estudo exploratório-descritivo de abordagem qualitativa. Participaram 12 adolescentes primigestas, frequentadoras dos serviços ambulatórios de saúde de Passo Fundo (RS). Por meio de entrevistas semiestruturadas, genogramas e ecomapas, obtiveram-se os dados analisados pela modalidade temática. Evidenciou-se a percepção da necessidade de apoio para superar o medo e o desafio da maternidade. Mães e parceiros foram percebidos como as principais fontes de apoio, provendo as dimensões afetiva e material. O saber do senso comum preencheu a dimensão de informação, e a dimensão emocional revelou a gravidez como mediadora na reconciliação com o pai. A percepção da dimensão de interação social positiva foi ofuscada pelo isolamento autoimposto. Assim, a percepção da adolescente sobre o apoio social recebido é nítida em relação ao núcleo familiar e circunscreve-se às pessoas com maior apego. A rede de cuidados extrafamiliar, incluindo os serviços de saúde, é frágil e gera a percepção das dificuldades psicossociais, sugerindo a necessidade de maior investimento dos profissionais da atenção básica de saúde na inserção das adolescentes primigestas em grupos de cuidado social, que influenciam no desenvolvimento saudável da gestação.

Palavras-chave Adolescência, Gestação, Apoio social 


\section{Introdução}

A adolescente, ao engravidar, convive com dois eventos estressores, que ocorrem sinergicamente: a adolescência e a gestação. A adolescência, por si só, implica investimentos pessoais e sociais para lidar com as mudanças físicas e emocionais, mas também com o posicionamento social, familiar e sexual. Em relação à gestação, a adolescente se vê desafiada a assumir um maior grau de independência e de responsabilidade pela provisão de cuidados com o desenrolar da gestação. Entretanto, a transição entre a posição de indivíduo que recebe cuidados para a de sujeito que oferece cuidados ocorre, geralmente, num contexto de coabitação e dependência sociofamiliar. A libertação desse contexto pode se dar pelo casamento ou pela maternidade, tidos como vias de mais rápido acesso à fase adulta, ainda que a opção pela gravidez encerre o ônus da ilegitimidade social da maternidade precoce, atribuída frequentemente à "irresponsabilidade" adolescente. Essa conotação assenta-se sobre o pânico moral, advindo de um clima social que atribui as condições insatisfatórias de vida em sociedade à dissolução moral, à falta de autoridade na família, à redefinição de papéis de gênero e ao exercício da sexualidade em novos termos ${ }^{1}$. Nessa concepção, a adolescente deveria adotar os padrões reprodutivos impostos pelo ambiente sociocultural em que está inserida.

O estatuto de "problema social" conferido à gravidez na adolescência decorre da interpretação dada a ela pelos seguintes enfoques²: (1) médicoepidemiológicos - assentam-se sobre os fatores de riscos para a saúde das mães e seus filhos associados à idade reprodutiva; a gestação "precoce" decorre da grande suscetibilidade a comportamentos de risco; (2) sociodemográficos - enfocam o aumento quantitativo de mães solteiras decorrente da instabilidade de vínculos conjugais e a interrupção do processo de escolarização da adolescente, com repercussão sobre seu futuro no mundo do trabalho e, consequentemente, na sua situação social e econômica; (3) psicossociais seus argumentos apoiam-se sobre a autonomia da adolescente em relação à família de origem e a sua capacidade de assumir responsabilidades sociais; neste enfoque, a gravidez na adolescência é tida como produto de instabilidade familiar, pobreza, abandono escolar, carência psicoafetiva; estaria, portanto, vinculada à possibilidade de perpetuação da pobreza e nesta condição deveria ser coibida pela sociedade como forma de redução das desigualdades socioeconômicas.
O deslocamento desses enfoques para a concepção da gravidez na adolescência como uma etapa do aprendizado da sexualidade juvenil parte da compreensão da juventude como um processo de aquisição gradativa de liberdade e autonomia. Nessa dimensão, a gravidez é percebida com diferentes possibilidades e significados entre os jovens de diferentes contextos sociais ${ }^{1}$. Assim, a vivência da sexualidade concorre para a construção social do adolescente e o capacita a captar os padrões socioculturais e a desenvolver as possibilidades de se tornar independente dos pais sem, contudo, dispensar o seu apoio ${ }^{3}$.

A decisão de assumir a maternidade condiciona a adolescente, na maior parte dos casos, a aceitar o apoio familiar nas suas dimensões material, de informação, afetiva, entre outras, que lhe permitem enfrentar os desafios do percurso escolar-profissional e da convivência com o parceiro e sua família ${ }^{4}$, sem implicar ruptura nas suas trajetórias de vida e no seu processo de individualização.

Algumas adolescentes, no entanto, sentindose empobrecidas de cuidado intrafamiliar durante a gestação, podem reduzir os seus contatos sociais e enfraquecer os vínculos de amizade. Por esses vínculos, poderiam estar fluindo as dúvidas e as inquietações íntimas, mais fáceis de serem compartilhadas com pessoas da mesma idade e ambiente socioeconômico do que com profissionais, especialmente quando são poucos os espaços para escuta e manifestações de necessidades. Nas relações de amizade ou vizinhança podem circular informações acerca da vivência da sexualidade e da gestação, que complementam a orientação técnica. Desse modo, os cuidado formal e informal se articulam oferecendo a possibilidade de compreensão da gravidez e seus desdobramentos numa perspectiva sociocultural por meio da solidariedade e do apoio mútuo entre pessoas do mesmo grupo social.

O setor saúde redescobriu a família como unidade privilegiada de atenção ao implantar a Estratégia Saúde da Família. Fica implícito nesta política governamental o reconhecimento de que a família está no centro das funções de cuidado. Esse tipo de cuidado de conotação social efetivase nas relações de parentesco, de vizinhança e de amizade e no atendimento das necessidades físicas e emocionais das pessoas envolvidas. Configura-se, portanto, como um cuidado não profissional, que tenta romper com o atendimento individualizado para envolver a família como sujeito autônomo de produção do cuidado na linha das relações sociais. Inclui, assim, a possi- 
bilidade de equilibrar a relação entre cuidado formal e informal e fortalecer o apoio social à gestante adolescente.

No entanto, a existência do apoio social entendido aqui como todo o suporte dado pela família ou pelos amigos, que faz a adolescente grávida sentir-se cuidada em suas necessidades físicas, compreendida, acompanhada, assistida e orientada - pode não ser percebido como tal pela adolescente, impedindo-a de alcançar a sensação de bem-estar e de desenvolver a capacidade de enfrentamento dos problemas.

O apoio social é um processo dinâmico e complexo. Envolve transações entre indivíduos e as suas redes sociais, satisfazendo as necessidades sociais, promovendo e completando os recursos pessoais que possuem para enfrentarem novas exigências ${ }^{5,6}$.

As funções do apoio social se dividem em apoio emocional - que inclui disponibilidade de alguém com quem se possa falar e que fomenta sentimentos de afeto; apoio material e instrumental - que se caracteriza por ações ou materiais proporcionados por outras pessoas para facilitar ou diminuir tarefas cotidianas; e, por fim, o apoio de informação - que se refere às informações e orientações recebidas, que ajudam na compreensão do mundo ${ }^{7}$.

"Perceber" o apoio social como disponível em situação de necessidade é um redutor potente do estresse, mais do que o realmente recebido ${ }^{8}$. O apoio social ameniza os efeitos patogênicos do estresse no organismo, estimulando a capacidade das pessoas para lidar com situações difíceis 9 .

Existem variações na percepção que o indivíduo tem sobre o apoio social. Esta percepção encontra-se ligada pela comunicação aos sujeitos de que são estimados e pela confiança que adquirem pela constatação de que os outros se interessam por eles e estão disponíveis quando for necessário. Quando o apoio social é percebido, é interiorizado de forma cognitiva e com origem nas experiências de apego. Assim, o apoio social recebido será efetivo de acordo com o entendimento de cada indivíduo.

Desde a década de 1970, há estudos que relacionam laços sociais e saúde $e^{10,11}$ e mostram que o apoio social atuaria tamponando a resposta do organismo em forma de doença e, também, fortalecendo a sensação de controle sobre a própria vida, com efeitos positivos para a sua saúde. Posteriormente, evidenciou-se ser extremamente importante desenvolver estudos a respeito do apoio social para o planejamento e o desenvolvimento de políticas e programas de saúde, priori- zando o ambiente psicossocial, considerando também os fatores biológicos e psicológicos ${ }^{12}$.

Entre os estudos realizados nesta perspectiva, está o desenvolvido por Silva ${ }^{13}$, que teve como objetivo identificar o papel do apoio social sobre a ocorrência da pré-eclâmpsia. Os resultados da pesquisa mostraram que multíparas com maior nível de apoio social tendem a reduzir o risco de apresentar sintomas de pré-eclâmpsia. Para as primíparas, houve maior nível de apoio social com consequente redução dos sintomas da doença ${ }^{10}$.

Em relação à percepção do apoio social na gestação, um estudo realizado com mães adolescentes e adultas ${ }^{14}$ mostrou que possuir uma rede de apoio social permitiu a essas mães sentiremse amparadas.

Nesta lógica, este estudo objetivou desvelar a percepção da gestante adolescente sobre o apoio social recebido, possibilitando sensibilizar os profissionais de saúde para a criação de grupos de cuidado social no âmbito de suas áreas de atuação, recuperando as redes de solidariedade primárias como provedoras de cuidados informais.

\section{Metodologia}

Trata-se de uma pesquisa exploratório-descritiva de abordagem qualitativa desenvolvida em dois Centros de Atenção Integral à Saúde do município de Passo Fundo (RS). Essas unidades foram escolhidas por ali existirem grupos de gestantes adolescentes em funcionamento. O município de Passo Fundo integra a Macrorregião Norte de Saúde do Estado do Rio Grande do Sul (RS) e conta com uma população estimada para 2007 de 188.302, com uma taxa de crescimento anual de 1,9\% estimada para o período 2000 2006. As gestações na adolescência corresponderam a $19,7 \%$ no período de julho a dezembro de $2006^{15}$. Na atenção básica de saúde, a cobertura em 2005 pelo Programa de Agentes Comunitários de Saúde atingiu 23,51 (12,4\%) habitantes e pela Estratégia Saúde da Família, $54.271(29,3 \%)^{16}$.

Participaram do estudo doze adolescentes primigestas, frequentadoras dos serviços de saúde há, no mínimo, um ano. Esse número foi definido pela saturação de dados. A escolha das participantes foi feita de forma intencional deliberativa, por ser impossível, por questões práticas, abordar todos os sujeitos que compõem o grupo de interesse do pesquisador; só é viável conhecer parte do universo ao que denominamos de amostra de sujeitos. O autor do projeto delibera quem são os sujeitos que comporão seu estudo, ficando livre 
para escolher entre aqueles cujas características possam trazer informações substanciosas sobre o assunto em pauta ${ }^{17}$. Estabeleceu-se como critério de exclusão as adolescentes primigestas com comunicação prejudicada.

A captação das gestantes para o estudo foi feita pelas pesquisadoras, com colaboração das equipes de Saúde da Família das unidades selecionadas para o estudo. O contato foi estabelecido durante a participação delas nos grupos educativos que funcionam nesses locais.

A coleta dos dados foi realizada em dois momentos:

- Primeiro momento: por meio de entrevistas semiestruturadas, com auxílio de um instrumento contendo: (1) dados sociodemográficos; (2) construção de genograma e ecomapa; (3) questões abertas sobre a rede de apoio familiar, de vizinhança, grupo de convívio e serviço público relativas às dimensões investigadas: apoio material, apoio afetivo, apoio emocional, apoio de informação e interação social positiva.

O genograma corresponde a um diagrama que detalha a estrutura e o histórico familiar fornecendo informações sobre vários papéis de seus membros e das diferentes gerações.

O ecomapa é um diagrama das relações entre a família e a comunidade. Serviu como instrumento complementar para a identificação das dimensões funcionais de apoio social percebido propostas por Ostergren et al. ${ }^{18}$ e Sherboune e Sterwart ${ }^{19}$ e empregadas no Brasil, entre outros, por Griep et al..$^{20}$ e Pinto et al. ${ }^{21}$, assim descritas: (1) “apoio material": refere-se à provisão de recursos e ajuda material, incluídas, por exemplo, a ajuda em dinheiro ou empréstimo de utensílios, em caso de necessidade emergencial; (2) "apoio afetivo": envolve demonstrações físicas de amor e afeto; (3) "apoio emocional": refere-se à expressão de carinho, compreensão, confiança, estima, afeto, escuta e interesse; (4) "apoio de informação": refere-se à disponibilidade de pessoas para a obtenção de conselhos ou orientações; é medido por meio do acesso dos indivíduos a aconselhamentos, sugestões, orientações e informações; (5) "interação social positiva”: é a disponibilidade de pessoas com quem se divertir e relaxar. Essas dimensões integram as escalas de apoio social empregadas em estudos quantitativos e servirão de parâmetros para a avaliação da percepção sobre o apoio social recebido, numa abordagem qualitativa.

- Segundo momento: foi realizada uma dinâmica de grupo, com técnica projetiva, na qual o grupo se autoanalisou e autointerpretou.
Tratando-se de uma pesquisa qualitativa, empregou-se a análise de conteúdo, optando-se pela técnica temática, que se destina a descobrir os núcleos de sentido presentes no conteúdo das falas e com significado para o objetivo de análise do pesquisador ${ }^{22}$.

O projeto de pesquisa foi apreciado e aprovado pelo Comitê de Ética em Pesquisa da Universidade de Passo Fundo. O seu desenvolvimento junto às unidades de saúde foi autorizado pelo secretário municipal de saúde. Cada participante e seus representantes legais assinaram o Termo de Consentimento Livre e Esclarecido. Os casos identificados com carência de apoio foram encaminhados para a Unidade de Saúde da Família a que pertence.

\section{Resultados e discussão}

Participaram deste estudo 12 adolescentes com idades entre 14 e 19 anos, nove delas casadas ou com união estável. Todas interromperam os estudos ao engravidar. Nove estavam cursando o ensino médio e três o fundamental. Eram em sua maioria católicas e não trabalhavam. Cinco delas permaneceram na casa dos pais após a gravidez, cinco foram morar com a família do parceiro (a expressão "parceiro" será utilizada no texto com o sentido de marido ou companheiro) e duas constituíram o próprio lar com o pai da criança.

Apesar de haver uma tendência atual de vincular a gravidez na adolescência ao processo de individualização juvenil, considerado como o modo de construção social do jovem ${ }^{3}$, neste estudo foi adotado o recorte etário de 10 a 19 anos estabelecido no conceito de adolescência da Organização Mundial da Saúde ${ }^{23}$, porque era de interesse compreender o apoio social percebido pelas adolescentes em fase de escolaridade média, pertencentes a classes econômicas médiobaixas, que acessam os serviços da rede municipal de saúde.

A média de idade das gestantes foi de 17 anos $(\mathrm{DP}=1,8)$, o que revela um padrão similar ao encontrado em três capitais brasileiras no estudo intitulado "Gravidez na Adolescência: estudo multicêntrico sobre jovens, sexualidade e reprodução no Brasil” (Projeto Gravad) ${ }^{24}$. Apenas cinco das doze adolescentes engravidaram antes de atingir sua maioridade civil, permanecendo assim com o direito de receber sustento familiar ${ }^{25}$. No entanto, a despeito da formalidade legal, algumas gestantes se deparam com o fantasma da punição: A minha irmã ficou grávida aos 14 anos, 
então eu pensei que o meu pai fosse me crucificar porque de novo aconteceu a mesma coisa, sendo que eu já tinha visto o meu pai e a minha mãe sofrerem com a minha irmã. Ele me criticou claro, disse que eu ia sofrer as consequências, mas não me expulsou de casa, nem nada. Eu fui morar com a minha sogra porque meu namorado achou melhor, minha família nunca me mandou embora (A1, 16 anos, união estável). Percebe-se o discurso moralista subjacente à expectativa da adolescente acerca da conduta paterna diante da repetição da vergonha e do sofrimento imputados pela gestação na adolescência. A quebra das expectativas tradicionais da maternidade dentro do casamento e em idade socialmente legitimada parece justificar o uso da punição por meio da ruptura do dever familiar de sustento, conferido pela legislação atual. Mas não é o descumprimento desse dever que move a expulsão de casa e sim a demonstração da indignação pelo ocorrido, mesmo que, como neste caso, circunscrita ao imaginário da gestante e ao gênero feminino.

A idade dos parceiros variou de 20 a 31 anos (média 24; DP: 3,6). Nenhum deles, portanto, adolescente. Três eram mais velhos (2-4 anos) e nove muito mais velhos ( 5 anos e + ) do que a adolescente, tendência também constatada no Projeto Gravad ${ }^{24}$. Essa tendência reflete a desigualdade de gênero no relacionamento afetivosexual, cuja expectativa recai na união de mulheres mais jovens com homens mais velhos ${ }^{26}$.

No que tange à situação conjugal, no universo estudado houve predomínio de uniões estáveis, formais ou não, em coabitação com os pais da adolescente ou de seu parceiro. A gravidez ocorreu numa etapa do processo vital em que o jovem casal não havia ainda alcançado a independência material e domiciliar em relação aos seus pais, fenômeno que contribui para modular o chamado "prolongamento da juventude" 26 Concorre ainda para esse processo a interrupção da trajetória escolar das gestantes e o adiamento da sua profissionalização. Essas duas situações - autonomização familiar-residencial e escolar-profissional - constituem o limiar de ingresso à vida adulta ${ }^{1}$. Nesse percurso em direção à adultez, pressupõe-se que a adolescente necessita não somente receber apoio social, mas percebê-lo como tal.

\section{Percepção da adolescente primigesta acerca do apoio social recebido}

Da análise dos conteúdos das entrevistas, dos genogramas e dos ecomapas emergiram as seguintes categorias temáticas derivadas da "percepção da adolescente primigesta”: necessidade de apoio para superar o medo e o desafio da maternidade; as avós e os parceiros como fontes supridoras de apoio. Nas "dimensões do apoio" destacaram-se: a necessidade não percebida de apoio material; a experiência das mais velhas e o saber profissional; o amor do parceiro e a compreensão materna; a gravidez como mediadora na reconciliação com o pai e a percepção ofuscada pelo isolamento autoprovocado.

\section{Necessidade de apoio para superar o medo e o desafio da maternidade}

O apoio social oferece a proteção da pessoa a algum evento da vida que possa lhe imputar sofrimento. No caso da gravidez inesperada e em idade precoce, os mecanismos de proteção mais efetivos são geralmente buscados no núcleo familiar e nos contatos sociais. Contudo, em algumas famílias, a gravidez na adolescência pode ser de difícil aceitação e provocar conflitos familiares que se tornam fontes de problemas para as adolescentes: Tenho dificuldade com a minha sogra. Um pouco ela quer o neto, outro pouco não quer, ela não se decide. Às vezes acontece alguma coisa e ela joga a culpa na criança. Por exemplo, meu namorado perdeu o emprego e ela disse que se tivesse tirado [abortado] não precisava se preocupar. Ela não perde oportunidade de me alfinetar (A6, 19 anos, união estável). Em cenário familiar igualmente adverso, outra adolescente resistia ao desamparo e à recriminação: $S e$ eu estivesse vomitando, ela [sogra] deixava que eu me virasse e ainda dizia: "Viu, quem mandou engravidar? Agora aguenta! Se tivesse tirado, como eu disse..." (A1, 16 anos, união estável). Nesses ambientes marcados pela tensão, o apoio social é percebido como muito aquém do necessário para minimizar o sofrimento e enfrentar o desafio da maternidade. Nas duas situações descritas, o arranjo familiar adotado pelo jovem casal foi a coabitação com os pais dele, que pode refletir o sentido de provedor que a sociedade espera do pai como requisito para lhe conferir a identidade masculi$\mathrm{na}^{4}$. Para algumas gestantes adolescentes, no entanto, esse arranjo as desonera, assim como suas famílias, das responsabilidades com as despesas acrescidas pela maternidade, porém impõe-lhes 
uma sobrecarga psíquica, nem sempre compartilhada numa rede de cuidados.

O sofrimento pode advir também da inconformidade da própria adolescente com a gravidez inesperada e indesejada: A minha vontade era de tirar, mas quando descobri que estava grávida não deu mais tempo, agora vou ter. O pai da criança nem sabe que eu estou grávida e eu não vou contar, porque ele não vai acreditar, nos conhecemos e namoramos só uma noite (A3, 17 anos, reside com parceiro). O inconformismo se expressa com sentimentos auto e heteropunitivos: Quando descobri que estava grávida [...] queria tirar, não aceitava de forma alguma. Senti ódio, raiva, vontade de sair correndo. Senti mais raiva ainda do pai da criança, não queria ver ele na minha frente, parecia que ele era o culpado por tudo (A5, 14 anos, união estável). Nessa turbulência emocional, a adolescente identifica o medo de revelar a gravidez e a sensação de incapacidade de exercer a maternidade como os fatores que a fazem perceber a necessidade de apoio para acatar os constrangimentos impostos pela norma contraceptiva ${ }^{3}$.

A discordância entre a posição das adolescentes de prosseguir com a gestação e a posição dos familiares do companheiro favorável à interrupção acirra os conflitos, como vimos nos depoimentos das quatro jovens que vivenciaram essa situação. Contudo, o ônus da escolha e seu enfrentamento podem ser incorporados no processo de construção da identidade juvenil, quando decorrem de escolhas autônomas, sem imposição ${ }^{3}$. Mas há que se considerar também que a adolescente não transita por essa fase vital sem apoio familiar. Com escassas condições psicossociais para assumir o novo papel, amedrontada e insegura, a adolescente reconhece o apoio social como mediador na reestruturação das relações afetivas abaladas e como fator de mobilização de recursos pessoais que possam fortalecê-la emocionalmente e melhorar sua capacidade de enfrentamento das demandas acrescidas pela gestação e maternidade.

Gestos de carinho, aceitação, diálogo e coerência em imposições de regras e disciplina contribuem para que a adolescente se sinta amada, cuidada e protegida pela família. Através dessas atitudes, a adolescente terá menor probabilidade de sofrer traumas emocionais e poderá construir sua identidade, a partir de uma visão otimista e realista de si mesma ${ }^{27}$. A gestação, como desfecho do exercício afetivo-sexual, proporciona o desenvolvimento da autonomia pessoal e aprofunda a interação com a rede de relacionamentos.

\section{As mães e os parceiros como fontes supridoras de apoio}

Seis das doze adolescentes entrevistadas perceberam a sua mãe como a principal fonte de apoio social, independentemente da aceitação ou não da gravidez da filha ou de coabitarem. A constituição de uma rede familiar é um sustentáculo relevante no projeto de individualização da adolescente, por suportar a carga da vida cotidiana numa trajetória permeada por desigualdades sociais, culturais e de gênero. $\mathrm{O}$ apoio materno possibilita à adolescente a construção de capacidades para lidar com as novas relações que se estabelecem no interior dos relacionamentos conjugais e familiares em decorrência da gestação e da coabitação. Representa também um refúgio seguro para os momentos de indecisão, insegurança e solidão.

Para outras quatro gestantes, a principal fonte de apoio foi o parceiro. Nos seus ecomapas percebia-se forte vinculação com a família de origem, especialmente com os pais, o que leva a supor que embora se percebessem mais apoiadas pelo parceiro, podiam contar também com o apoio familiar. Outros estudos ${ }^{28,29}$ indicam que as adolescentes, ao engravidar, buscam inicialmente o apoio do parceiro e, em seguida, da mãe e de amigos.

Para as demais adolescentes, a sogra representou o apoio necessário e constante, corroborando o que dizem outros autores que destacam o papel das avós no cuidado e sustento de seus netos ${ }^{4}$. Em muitos casos, esse cuidado inicia na gestação.

Em estudo realizado por Piccinini et al. ${ }^{14}$, as mães adolescentes referiram requerer maior apoio de familiares e de outras pessoas do que as mães adultas, que assumiram mais atividades relacionadas aos cuidados com a criança e com as tarefas domésticas. Os resultados apontaram a contribuição do apoio social para uma experiência mais positiva da maternidade, especialmente para as mães adolescentes.

A partir da segurança advinda do sentimento de constância no cuidado, a adolescente estabelece a capacidade individual de interagir com outras pessoas. Esse processo que se inicia na infância precisa ser renovado e fortalecido na adolescência. A segurança advinda do apoio social capacita a adolescente para a aquisição de autonomia e ampliação da rede social com a inclusão de colegas, amigos, professores e outras pessoas. O sentimento de segurança assim formado ten- 


\section{Dimensões do apoio social recebido}

Neste estudo, evidenciamos as dimensões de apoio social indicadas a seguir.

\section{Apoio material: \\ a necessidade não percebida}

Essa dimensão é caracterizada pelas ações ou materiais proporcionados por outras pessoas para facilitar ou diminuir as tarefas cotidianas e foi pouco percebida pelas gestantes, mesmo por aquelas com poucas condições financeiras. É possível que as preocupações vivenciadas com a própria gestação e o fato de estarem morando com as famílias de origem ou do parceiro, supridoras de suas necessidades materiais, tenham contribuído para esse esmaecimento da percepção de apoio material refletida na seguinte fala: Me deram roupa, mas pouca coisa. Mas eu tenho ele, né, ele me ajuda, a mãe dele me ajuda, o pai dele também, no sentido de comprar coisas pro nenê. Tenho tudo. Agora tô bem (A2, 18 anos, união estável).

Mesmo com ofuscada percepção por parte da adolescente, a família configura-se como uma instância de apoio afetivo-material pela qual transita a construção de autonomia e redimensionamento da relação de dependência do jovem casal ${ }^{4}$.

\section{Apoio de informação: a experiência das mais velhas e o saber profissional}

Essa dimensão se refere às informações $e$ orientações recebidas, que ajudam na compreensão do mundo ${ }^{30}$. Configura-se como essencial na gestação, especialmente quando provida por profissionais de saúde, uma vez que nela estão as orientações sobre o processo gestacional e os cuidados para o desenvolvimento saudável do feto, além dos mecanismos para lidar com os problemas pessoais e com as informações contraditórias que a adolescente recebe das pessoas com quem convive.

Das doze entrevistadas, apenas uma se referiu à médica como uma fonte supridora de suas necessidades de esclarecimento e compreensão. Os ecomapas demonstram claramente esse vácuo dos serviços de saúde na configuração da rede de apoio dessas adolescentes. Ao menos essa é a percepção delas acerca da participação dos profissionais no suprimento das orientações. Destaca-se que todas participavam de grupos de gestantes vinculados às Unidades Básicas com Estratégia Saúde da Família. Essa estratégia tem no pré-natal um dos pontos fortes da assistência, devendo acolher todas as necessidades da mulher, desde o momento em que ela procura os serviços. No entanto, a gestante deve ser envolvida, assim como sua família, na produção do cuidado em espaços coletivos e interativos. Diante disso, questiona-se: até que ponto as equipes estão oportunizando a expressão das dificuldades e dúvidas dessas futuras mães ou estão utilizando uma metodologia de trabalho participativa, que permita à gestante reconhecer essa ação como um apoio colocado a sua disposição e inserido na sua rede social?

De todo modo, as falas refletem que o saber do senso comum prevalece sobre o conhecimento técnico no que se refere ao esclarecimento da gestante: Eu falo com a minha mãe e com as minhas primas que são mais velhas e eu me criei com elas. A gente fala de neném, cuidados com a amamentação, sono, fraldas, para não assar o bebê. Esse tipo de assunto elas me ensinam o que sabem, o que fizeram quando os filhos eram pequenos (A3, 17 anos, reside com o parceiro).

As mães foram as grandes supridoras de informações para essas adolescentes, revelando mais uma vez a participação da família como um fator muito positivo, considerando-se que $a$ família deve ser incluída na assistência à gestante para que possa servir como suporte às consultas indicadas pelos profissionais durante a gestação estabelecendo um processo saudávell1.

\section{Apoio afetivo: o amor do parceiro e a compreensão materna}

A dimensão afetiva é aquela que oferece à gestante adolescente a possibilidade de ter alguém que expresse amor a ela por meio de gestos, abraços ou qualquer outra demonstração que a faça sentir-se querida e amada. Para a maioria das entrevistadas, a mãe é a grande fonte de apoio afetivo, também suprido pelos parceiros. $\mathrm{Na}$ trajetória para a vida adulta e para a maternidade, $o$ apoio afetivo consubstancia-se como mais um elemento favorável no contexto de redimensionamento da dinâmica familiar.

Nessa mesma perspectiva, a proteção que reflete a capacidade de se relacionar bem com o parceiro contribui para o desenvolvimento da 
competência social, ou seja, da capacidade de interagir de maneira eficaz com os outros e com o ambiente social ${ }^{32}$. Neste estudo, essa competência foi mais bem evidenciada entre as gestantes que coabitavam com o parceiro. Essa competência permite reforçar a autoestima e a autoeficácia, a autoavaliação positiva e crítica, regular emoções e sentir empatia pelos outros, entre outras estratégias ${ }^{1}$ para o alcance da autoconfiança necessária ao desempenho do papel materno, que esteve nas preocupações verbalizadas por várias das entrevistadas.

Assim, a qualidade do apoio afetivo e seguro constitui uma base sólida para que a adolescente mantenha durante a gestação seu desenvolvimento emocional, sua socialização, a organização dos papéis e das relações com a comunidade e, acima de tudo, a construção do sentimento de afeto por si própria, o que lhe permitirá elevar a autoestima e ter maior satisfação com a vida ${ }^{27}$.

\section{Apoio emocional: a gravidez como mediadora na reconciliação com o pai}

O apoio emocional se expressa na escuta da adolescente e de seus problemas, de seus anseios e preocupações, de suas inquietudes mais íntimas e também de contar com alguém com quem possa relaxar. Nesta dimensão, três adolescentes fizeram eclodir sentimentos represados relacionados aos pais. Duas mantinham relações conturbadas prévias à gestação; outra, após revelar a gravidez, havia se afastado dos pais por imposição do parceiro com quem vivia de forma economicamente independente. $\mathrm{O}$ afastamento afetivo gerava um sofrimento que parecia amainado pela gestação: Sinto falta de meu pai, nunca conseguimos nos entender, nossos temperamentos não fecham, eu não concordo com o jeito dele pensar. Ele é muito rígido, só ele sabe e decide, mas mesmo assim gostaria de dividir essa alegria com ele. Faz uns seis meses que não nos falamos, espero me acertar com ele (A10, 14 anos, gestação planejada, união estável). Para a outra adolescente, a reversão do relacionamento conflituoso foi decorrente da gestação: Nunca me dei com meu pai, ele sempre foi grosso, mas agora ele até traz alguma coisa diferente para eu comer (A9, 19 anos, casada). Para essas adolescentes, a reconciliação e a confiança no amor paterno, mediadas pela gestação, contribuíram para a recuperação do bemestar e a redução dos conflitos.

A família saudável não é aquela imune a problemas, mas a que possui potencial para solucionar conflitos, reduzir seus efeitos destrutivos e valorizar seus ganhos. Diante da gestação, as adolescentes puderam reexaminar suas identidades e papéis e contrabalançar os conflitos com os pais, a partir do reconhecimento de seus gestos afetivos. A figura paterna foi ressignificada e valorizada, abrindo perspectivas para relacionamentos mais harmônicos.

\section{Interação social positiva: a percepção ofuscada pelo isolamento provocado}

A dimensão interação social positiva reflete a convivência estabelecida para a diversão e a realização de atividades prazerosas. A maioria das adolescentes percebeu essa dimensão atendida pelos familiares e parceiros. No entanto, essa dimensão ficou comprometida para três adolescentes entrevistadas, que optaram pelo recolhimento, conforme se observa nestas falas: Eu fico só em casa, não saio por nada, no máximo eu vou ao Cais [Centro Integral de Atenção à Saúde unidade de saúde com atendimento básico e especializado], às consultas, não tenho vontade de falar ou ver ninguém. Estou feia, gorda, e as pessoas ficam me olhando estranhas (A9, 19 anos, casada). Não tô deixando mais muita gente chegar perto de mim, fazer amizades (A10, 14 anos, gestação planejada, união estável).

Num dos casos, a autoimagem está comprometida, no outro é a confiança que está abalada. Quando um evento - como uma gravidez - acarreta mudança interna na pessoa, alterando ou comprometendo seus recursos adaptativos, pode ser considerado um estressor, dependendo da situação, da história pregressa e do estágio de desenvolvimento em que a adolescente se encontra ao se defrontar com o problema ${ }^{34,35}$. A gravidez, neste caso, parece ser o estressor responsável pelas dificuldades psicossociais a que as adolescentes se percebem submetidas. Para uma delas, a busca do serviço de saúde revelou-se a alternativa terapêutica; para outra, o serviço parece representar o cumprimento de uma obrigação, sem encontrar nesse locus a identificação e as estratégias para a minimização dos seus problemas. Contudo, o fato de frequentarem o serviço é animador, especialmente diante de um isolamento autodecretado que ofusca a percepção do potencial de interatividade social dele. Ao realizarem as consultas, as gestantes podem desenvolver o vínculo com o profissional, elemento necessário para que se sintam em condições de expor as suas apreensões e receber do profissional de saúde o apoio social que possa amenizar os efeitos negativos do estresse no organismo, esti- 
mulando nelas a capacidade para lidar com situações difíceis. Com isso, aumenta-se a vontade da pessoa de viver, com melhora da autoestima, contribuindo para o enfrentamento desse momento de crise ${ }^{7}$.

\section{Percepção do apoio social não suprido: a emergência dos ressentimentos}

Ao desvendar a percepção das adolescentes sobre o apoio social, percebe-se que a maioria sente-se satisfeita com a rede de cuidados estabelecida em torno de si. Elas pontuam o momento de revelar a gravidez como o mais difícil de enfrentar sozinhas. Como isso já ocorreu, a tensão foi aliviada. No entanto, diante do apoio não suprido, surgiu uma explosão de sentimentos abafados e ressentidos, como este: Nunca tive o apoio de ninguém da minha família, mas pedi pra depois ficarem me jogando na cara? Prefiro sofrer do que ficar me humilhando (A2, 18 anos, união estável).

Felizmente, esse tipo de fala provém da minoria das entrevistadas, que não contam com o apoio que gostariam, especialmente da família do pai da criança. Aquelas com pouca oportunidade de conversar com a própria mãe também se sentiram carentes desse tipo de atenção, o que reforça mais uma vez a centralidade da figura materna como apoio indispensável nessa etapa do ciclo vital e a feminilização da rede de cuidados à gestante 4 .

No entanto, a postura de se tornar gradativamente independente do jugo familiar constitui um movimento esperado na trajetória de construção social da jovem ${ }^{1}$. Essa autonomia progressiva necessita ser relativizada no contexto da classe socioeconômica médio-baixa, em que estão inseridas as adolescentes deste estudo, uma vez que elas interromperam seus projetos escolares e estão vivendo na dependência material dos pais ou sogros. Nessas circunstâncias, vislumbra-se o prolongamento dessa dependência financeira e residencial, o que pode postergar o alcance da almejada autonomia, que caracteriza a entrada na vida adulta. Esta situação, no entender de Heilborn et al. ${ }^{1}$, mesmo que prolongada, assume um caráter mais conjuntural do que estrutural, e no caso das participantes deste estudo remete para a possibilidade da ocorrência do fenômeno de "internalidade feminina/externalidade masculina”, sugerido pelo perfil das adolescentes entrevistadas - com abandono escolar, sem profissão e trabalho, com parceiros de nível escolar fundamental e médio, empregados. Nessa conjuntura, o diferencial de gênero se expressa na internalidade das mulheres dentro de casa, assumindo as tarefas domésticas e o cuidado com as crianças, o que lhes possibilita atingir com maior precocidade o status adulto, em oposição à externalidade masculina, que compensa o prolongamento da dependência residencial em relação aos pais, prolongando a juventude ${ }^{1}$.

\section{As dificuldades na busca do apoio: o recuo social como escudo da vergonha}

Questionadas sobre as dificuldades pessoais para tomar a iniciativa da interação social, as adolescentes tenderam a atribuir ao julgamento dos outros os fatores de seu afastamento, como se pode perceber nesta fala: Sinto que as pessoas olham para mim de uma forma diferente, como se eu tivesse algum problema. Minhas amigas se afastaram, os vizinhos só prestam para falar mal. Eu prefiro nem sair de casa. A coisa que eu mais gostava era ir no grupo de dança e tive que deixar de ir por causa da gravidez (A11, 14 anos, solteira, mora com os pais).

A forma como cada adolescente percebe as adversidades do seu meio determina a sua reação a elas. Se a sua percepção é de preconceito social com a gravidez em idade precoce, essa adolescente reage com a autoexclusão dos meios sociais e o afastamento das pessoas de seu grupo de convivência. Essa atitude, contudo, limita a possibilidade de apoio e de construção de uma comunidade protetora e revela a fragilidade da autoestima da adolescente. A autoestima é moldada nas relações cotidianas e é decisiva na relação do indivíduo consigo mesmo e com os outros, além de exercer influência marcante na percepção dos acontecimentos e das pessoas e também do comportamento e vivência de cada um² $^{2}$. Assim, a opção de recolhimento tende a agravar o problema. A solidão e o isolamento foram queixas mencionadas pelas adolescentes entrevistadas no Projeto Gravad como sintoma da internalidade feminina, caracterizada pelo afastamento do universo escolar e de trabalho, revelando que o grau de restrição difere entre os gêneros, sendo mais acentuado nas mulheres, independentemente de suas inserções sociais particulares ${ }^{1}$.

\section{Considerações finais}

A adolescência constitui uma transição crítica na trajetória do indivíduo, e no seu interior a gesta- 
ção configura-se como uma possibilidade no aprendizado e na experimentação sexual dos jovens, permeada por privações objetivas e subjetivas. Este processo investigatório sobre as percepções das adolescentes primigestas acerca do apoio social recebido apontou que: a adolescente percebe a necessidade do apoio familiar, especialmente para enfrentar os sentimentos de medo e a sensação de incompetência maternal; as mães e os parceiros constituem as principais fontes de apoio para prover as dimensões afetiva e material; na dimensão de informação prevalece o saber apoiado na experiência das mães e das avós, complementado pelo saber profissional; na dimensão emocional, a gestação exerceu um papel mediador importante no restabelecimento da confiança da adolescente no amor paterno, ressignificando a relação pai-filha.

No âmbito mais amplo das relações extrafamiliares, a gestação foi percebida como respon- sável pelas dificuldades psicossociais vivenciadas pelas adolescentes em decorrência da autoimagem comprometida ou da perda da confiança nas pessoas. Nesses casos, a busca do serviço de saúde como estratégia terapêutica sinaliza para o papel central dos profissionais de saúde na detecção de isolamentos autoimpostos, que impedem a adolescente de interagir e ampliar sua rede de apoio social. Recomenda-se, assim, que os profissionais de saúde invistam na formação do vínculo para inserir as adolescentes primigestas em grupos de cuidado social, provedores de cuidados informais, que influenciam no desenvolvimento saudável da gestação. A integração desses cuidados às atividades realizadas pelos serviços de saúde poderá efetivar-se nas unidades básicas de atenção a partir da identificação das famílias ou dos grupos sociais primários, não só como destinatários de ações assistenciais, mas também como copartícipes no processo de atenção à saúde.

\section{Colaboradores}

T Schwartz e R Vieira participaram igualmente de todas as etapas da elaboração do artigo; LTC Geib participou na orientação sobre concepção, planejamento, referencial teórico-metodológico, coleta, análise e interpretação de dados, redação e revisão do texto.

\section{Referências}

1. Heilborn ML, Salem T, Knauth DR, Aquino EML, Bozon M, Rohden F, Victora C, McCallum C, Brandão ER. Aproximações socioantropológicas sobre a gravidez na adolescência. Horizontes Antropológi$\cos 2002 ; 8: 13-45$.

2. Cabral CS. "Gravidez na adolescência” e identidade masculina: repercussões sobre a trajetória escolar e profissional do jovem. Revista Brasileira de Estudos de População 2002; 19(2):179-195.

3. Brandão ER, Heilborn ML. Sexualidade e gravidez na adolescência entre jovens de camadas médias do Rio de Janeiro. Cad Saude Publica 2006; 22(7):1421-1430.

4. Dias AB, Aquino EML. Maternidade e paternidade na adolescência: algumas constatações em três cidades brasileiras. Cad Saude Publica 2006; 22(7):1447-1458.

5. Thoits PA. Social support as coping assistance. Journal of Consulting and Clinical Psychology 1995; 54(4): 416-423.

6. Matos AP, Ferreira A. Desenvolvimento da escala de apoio social: alguns dados sobre a sua viabilidade. Psiquiatria Clínica 2000; 21(3):243-253.

7. Martins RM. A relevância do apoio social na velhice. Millenium on Line. [documento na Internet] 2005. [acessado 2005 maio 2]. Disponível em: http:/ /www.ipv.pt/millenium/Millenium31/9.pdf 
8. Nunes M. Apoio social na diabetes. Millenium on Line 2005; 31:135-149. [acessado 2005 maio 6]. Disponível em: http://www.ipv.pt/millenium/Millenium31/ 9.pdf

9. Andrade G, Vaistman J. Apoio social e redes: conectando solidariedade e saúde. Cien Saude Colet 2002; 7(4):925-934.

10. Cobb S. Social support as a moderator of line stress. Psychossomatic Medicine 1976; 38:300-314.

11. Cassel J. The contribuition of the social environment to host resistance. American Journal of Epidemiology 1976; 104:300-314.

12. Chor D, Griep RH, Lopes CS, Faersdein E. Medidas de rede social e apoio social no Estudo Pró-Saúde: Pré-testes e estudos piloto. Cad Saude Publica 2001; 17(4):887-896.

13. Silva KS. O apoio social como fator de proteção à préeclâmpsia [tese]. Rio de Janeiro: Universidade do Estado do Rio de Janeiro; 2005.

14. Piccinini CA, Rapoport A, Levandowski DC, Voigt PR. Apoio social percebido por mães adolescentes e adultas: da gestação ao terceiro mês de vida do bebê. Psico 2002; 33(1):9-35.

15. Rio Grande do Sul. Prefeitura de Passo Fundo. Secretaria da Saúde. Relatório técnico sobre gestações na adolescência. Passo Fundo: Vigilância Epidemiológica; 2007.

16. Rio Grande do Sul. Prefeitura de Passo Fundo. Unidades de Saúde. [documento na Internet]. [acessado 2007 mar. 26]. Disponível em: http://www.passofundo. rs.gov.br/capa.php?f_cd_pagina $=172$

17. Turato ER. Tratado da metodologia da pesquisa clínico-qualitativa: construção teórico-epistemológica, discussão comparada e aplicação nas áreas da saúde e humanas. Petrópolis: Vozes; 2003.

18. Ostergren PO, Hanson BS, Isacsson SO, Tejler L. Social network, social support and acute chest complaints among young and middle-aged patients in an emergency department: a case-control study. Social Science \& Medicine 1991; 33(3):257-267.

19. Sherboune CD, Stewart AL. The MOS social support survey. Social Science \& Medicine 1991; 32(6):705714.

20. Griep RH, Chor D, Faerstein E, Lopes C. Apoio social: confiabilidade teste-reteste de escala no estudo pró-saúde. Cad Saude Publica 2003; 19(2):625-634.

21. Pinto JLG, Garcia ACO, Bocchi SCM, Carvalhaes MABL. Características do apoio social oferecido a idosos de área rural assistida pelo PSF. Cien Saude Colet 2006; 11(3):753-764.

22. Minayo MCS. O desafio do conhecimento: pesquisa qualitativa em saúde. São Paulo: Hucitec; Rio de Janeiro: Abrasco; 1996.

23. World Health Organization (WHO). Young people's health: a challenge for society. Geneva: World Health Organization; 1986. (WHO Technical Report Series, 731).

24. Aquino EML, Heilborn ML, Knauth D, Bozon M, Almeida MC, Araújo J, Menezes G. Adolescência e reprodução no Brasil: a heterogeneidade dos perfis sociais. Cad Saude Publica 2003; 19(Supl.)2:S377-S388.

25. Barbosa AI. Maioridade civil e exoneração de alimentos no novo Código Civil. Jus Navigandi 2003; 7(63): [cerca de 11p.]. 2003. [acessado $2007 \mathrm{dez} .22$ ]. Disponível em: http://jus2.uol.com.br/doutrina/ texto.asp?id $=3846$
26. Cabral CS, Heilborn ML, Equipe Gravad. Uniões juvenis: descrição de um perfil. In: Seminário As famílias e as políticas públicas no Brasil. Belo Horizonte: [s.n]; 2005.

27. Associação Brasileira de Enfermagem. Adolescer: compreender, atuar, acolher: Projeto Acolher. Brasília: ABEN; 2001.

28. Griffiths EA, Olivo MA, Romero ZJ, Saldivia SJ. Características psicosociales de la embarazada adolescente en Valdivia. Cuad Med Soc 1994; 35(2):31-37.

29. Godinho RA, Schelp JRB, Parada CMGL, Bertonce1lo NMF. Adolescentes e grávidas: onde buscam apoio? Rev Latino-Am Enfermagem 2000; 8(2):25-32.

30. Martins RM. A relevância do apoio social na velhice. Millenium on Line 2005; (31):128-135. [acessado 2005 maio 20]. Disponível em: http://www.ipv.pt/ millenium/Millenium31/default.htm

31. Cianciarullo TI. Saúde na família e na comunidade. São Paulo: Robe Editorial; 2002.

32. Assis SG, Pesce RP, Avanci JQ. Resiliência: enfatizando a proteção dos adolescentes. Porto Alegre: Artmed; 2006.

33. Cecconello AM, Koller SM. Competência social e empatia: um estudo sobre resiliência com crianças em situação de pobreza. Estud Psicol 2000; 5(1):7193.

34. Tavares J, organizador. Resiliência e educação. São Paulo: Cortez; 2001.

35. Garmezy N. Stressors of childhood. In: Garmezy $\mathrm{N}$, Rutter M, organizadores. Stress, coping and development in children. New York: Johns Hopkins University Press; 1998. p. 43-105.

36. Sanches AV, Escribano EA. Medição do autoconceito. Bauru: Edusc; 1999.
Artigo apresentado em 20/02/2008

Aprovado em 30/10/2008

Versão final apresentada em 29/12/2008 